\title{
SISTEM VERIFIKASI BERKAS DAN PEMBERIAN NRBU UNTUK BAGIAN BADAN PELAKSANA LEMBAGA PENYEDIA JASA KONSTRUKSI BERBASIS WEB DENGAN PHP MYSQL
}

\author{
(Web Based File Verification and NRBU Allocation System for Executives at \\ Construction Service Provider Institution Using PHP MySQL)
}

\author{
Fernanda Dicky Ivansyah $^{[1]}$, Fitri Bimantoro ${ }^{[1]}$, Muhammad Hadi ${ }^{[2]}$ \\ ${ }^{[1]}$ Dept Informatics Engineering, Mataram University \\ Jl. Majapahit 62, Mataram, Lombok NTB, INDONESIA \\ ${ }^{[2]}$ Lembaga Penyedia Jasa Konstruksi NTB
}

Email: dickyivansyah143@gmail.com, bimo@unram.ac.id, hadi@gmail.com

\begin{abstract}
Abstrak
Lembaga Penyedia Jasa Konstruksi (LPJK) NTB merupakan cabang LPJK nasional yang berada di provinsi Nusa Tenggara Barat. Sistem verifikasi berkas dan pemberian Nomor Registrasi Badan Usaha (NRBU) di LPJK sejauh ini masih secara konvensional yaitu berupa pencatatan manual. Pengabdian masyarakat ini bertujuan mengembangkan sistem untuk melakukan pencatatan verifikasi berkas dan pemberian nomor registrasi badan usaha dalam bentuk digital menggunakan website dengan PHP dan basis data MySQL yang dapat dimanfaatkan dan digunakan oleh stakeholder dari LPJK NTB. Hasil pengujian kuisioner yang diberikan kepada dua orang pegawai LPJK bagian badan pelaksana menunjukkan bahwa pegawai yang setuju dan sangat setuju dibuat dan digunakannya aplikasi ini masing-masing bernilai 50\% dan 50\%. Yang artinya sistem ini sudah layak untuk diterapkan.
\end{abstract}

Keywords: verifikasi berkas, PHP, MySQL, kuisioner, NRBU.

\section{Pendahuluan}

\subsection{Latar Belakang}

Teknologi Informasi saat ini merupakan sebuah kebutuhan dalam melakukan setiap aktivitas di hampir setiap bidang, terutama di dalam sebuah instansi. Tuntutan setiap aktivitas ini yang menjadikan teknologi informasi sebagai bagian terpenting di dalam keberlangsungan kinerja yang sedang dijalankan oleh sebuah instansi. Di Indonesia praktik pengukuran kinerja dilakukan untuk menjawab TAP MPR No. IX/MPR/1998 tentang penyelenggaraan pemerintah daerah yang bebas dari korupsi, kolusi dan nepotisme dan UU No.28 tahun 1999 menyatakan tentang hal yang sama. Menjawab mandat tersebut maka dikeluarkan Inpres No.7 tahun 1999 tentang akuntabilitas kinerja instansi pemerintah yang mewajibkan seluruh instansi pemerintah menyusun perencanaan strategi, melakukan pengukuran kinerja dan melaporkannya sebagai wujud akuntabilitas. Salah satu hal ini menyebabkan teknologi menjadi pengaruh di dalam sebuah kinerja instansi, baik dalam bentuk sistem informasi berbasis teknologi komputer atau website, teknologi informasi dapat memberikan nilai tambah bagi organisasi sehingga kinerja sebuah organisasi menjadi efisien dan efektif.

Salah satu instansi yang menggunakan dan memanfaatkan teknologi informasi ini adalah Lembaga Penyedia Jasa Konstruksi LPJK memiliki peran besar dalam kegiatan pengukuran kinerja industri konstruksi Indonesia. Karena sudah memiliki cabang di seluruh Indonesia.Pengumpulan data melalui LPJK akan lebih mudah karena setiap perusahaan konstruksi memiliki kewajiban registrasi tiap tahun. LPJK juga dapat dengan mudah memberlakukan ketentuan bahwa setiap perusahaan konstruksi wajib untuk mengisi kuisioner kinerja perusahaan dan proyek sebagai salah satu syarat registrasi [1].

Sistem verifikasi berkas dan pemberian Nomor Registrasi Badan Usaha (NRBU) di LPJK propinsi Nusa Tenggara Barat sejauh ini masih secara konvensional yaitu berupa pencatatan manual dengan menggunakan excel. Pegawai yang bertugas akan mencatat tanggal verifikasi berkas secara manual, kemudian data tersebut direkap dengan dimasukkan ke basedata LPJK nasional. Sistem pencatatan manual ini memiliki banyak kekurangan, yaitu sulitnya melakukan verifikasi dan penomoran nomor registrasi badan usaha, pencarian pada data, serta resiko seperti kendala dalam hal ketepatan. Oleh karena itu dibutuhkan suatu aplikasi yang dapat meringankan dalam mengerjakan verifikasi berkas dan pemberian NRBU. 
Solusi yang diusulkan untuk menyelesaikan masalah yang ada saat ini adalah dibangun suatu aplikasi untuk mengelola verifikasi dan penomoran NRBU untuk memberikan kemudahan pada kantor LPJK khususnya pada bagian Badan Pelaksana.

\section{Tinjauan Pustaka}

\subsection{Sistem Informasi}

Sistem informasi terdiri dari dua kata, yaitu sistem dan informasi. Sistem menurut Fat adalah sebuah himpunan "benda" nyata atau abstrak ( $a$ set of thing) yang terdiri dari bagian-bagian atau komponen-komponen yang saling berkaitan, berhubungan, berketergantungan, saling mendukung, yang secara keseluruhan bersatu dalam satu kesatuan (Unity) untuk mencapai suatu tujuan tertentu secara efisien dan efektif [2].

Pengembangan sistem informasi LPJK telah dilakukan oleh banyak pengembang karena memang sangat dibutuhkan oleh seluruh LPJK yang ada di Indonesia. Sistem Informasi Database Sertifikat Keterampilan Kerja (SKTK) pada LPJKD Aceh berbasis Web telah berhasil dikembangkan yang digunakan untuk untuk membantu LPJK Provinsi Aceh untuk memasukkan data Sertifikat keterampilan Kerja (SKTK) [3]. Di Kalimantan Timur, sistem pendukung keputusan sertifikasi badan pelaksana juga sudah berhasil dikembangkan [4]. Aplikasi tersebut dibuat dengan tujuan kecepatan komputasi. Komputer memungkinkan para pengambil keputusan untuk melakukan banyak komputansi secara cepat dengan biaya rendah.

Pengembangan lainnya terkait penerimaan berkas juga berhasil dibuat pada LPJK provinsi Maluku [5]. Sistem Informasi tersebut dibuat untuk mempermudah user atau pengguna dalam melakukan verifikasi dan validasi berkas sehingga tidak menyulitkan staf dalam pencarian berkas atau dokumen ulang ketika berkas tersebut di butuhkan.

Selain sistem verifikasi untuk LPJK, terdapat pula penelitian sistem lain yang dibuat untuk memverifikasi berkas digital pensiun dan sertifikasi guru [6][7]. Kedua aplikasi ini memudahkan guru atau pensiunan untuk melihat dan mendapatkan informasi dalam mengurus kelengkapan berkas.

Berdasarkan penelitian-penelitian tersebut, terdapat kesamaan dalam merancang suatu sistem informasi LPJK dalam hal verifikasi berkas. Untuk itulah peneliti akan melakukan perancangan sistem informasi pada Lembaga Penyedia Jasa Konstruksi (LPJK) yang bertujuan untuk memberikan pelayanan yang baik dan memberikan kenyamanan bagi pegawai LPJK khususnya di bidang badan pelaksana. Aplikasi ini juga dirancang agar dalam melakukan verifikasi berkas lebih terkomputerisasi. Dalam proses pembuatan aplikasi ini menggunakan konsep MVC (Model, View and Controller).

\subsection{Sertifikasi}

Sertifikasi adalah proses penilaian kompetensi dan kemampuan profesi keahlian dan keterampilan di bidang jasa konstruksi menurut disiplin keilmuan dan atau keterampilan tertentu dan atau kefungsian dan/atau keahlian tertentu[8].

\subsection{Basis Data}

Basis data adalah sumber data yang digunakan secara bersama oleh seluruh pengguna dalam organisasi. Setiap pengguna yang berasal dari fungsi yang berbeda dalam suatu organisasi akan membutuhkan data yang berbeda untuk diguanakan dalam mengerjakan tugasnya sehari-hari. Sehingga view (pandangan) terhadap data untuk setiap pengguna berbeda [9].

\subsection{ERD}

ERD (entity relationship diagram) adalah Model Entity-Relationship yang berisi komponen-komponen Himpunan Entitas dan Himpunan Relasi yang masing-masing dilengkapi dengan atribut-atribut yang merepresentasikan seluruh fakta dari 'dunia nyata' yang kita tinjau, dapat digambarkan dengan lebih sistematis dengan menggunakan Diagram Entity Relationship (Diagram E-R) [9].

\subsection{PHP}

PHP adalah bahasa pemrograman yang dirancang untuk membangun aplikasi web. Ketika dipanggil dari web browser, program yang di tulis dengan PHP akan diuraikan didalam web server oleh interpreter PHP dan diterjemakan ke dalam dokumen HTML, yang selanjutnya akan ditampilkan kembali kedalam web browser. Karena program PHP dilakukan dilingkungan web server (server-side). Oleh sebab itu, seperti yang telah di kemukakan sebelumnya, kode PHP tidak akan terlihat pada saat user memilih perintah "View Source" pada web browser yang mereka gunakan [9].

\subsection{MySQL}

MySQL adalah multi-user database yang menggunakan bahasa SQL. MySQL termasuk RDBMS (Relation Database Manajement System) dalam konteks bahasa SQL".Umumnya informasi tersimpan dalam tabel-tabel yang secara logika merupakan struktur dua dimensi yang terdiri atas bari-baris data yang berada dalam satu atau 
lebih kolom. Baris dalam tabel sering disebut dengan instance dari data, sedangkan kolom sering disebut sebagai attribute atau field. Keseluruhan tabel itu dihimpun dalam satu kesatuan yang disebut database [9].

\section{Metode Pengabdian masyarakat}

\subsection{Metode Pelaksanaan Pengabdian}

Pelaksanaan pengabdian dilakukan dengan mengimplementasikan sistem yang sudah disiapkan sebelumnya dengan memanfaatkan website dengan DBMS mysql. Kemudian dilakukan pelatihan terhadap operator di Lembaga Penyedia Jasa Konstruksi NTB yang akan mengelola website kedepannya.

\subsection{Waktu Kegiatan}

Beberapa persiapan yang perlu dilakukan sebelum kegiatan pengabdian kepada masyarakat antara lain :
a. Melakukan wawancara untuk kebutuhan sistem yang akan dibuat
b. Menetapkan hari, tanggal kegiatan, tempat serta peralatan yang perlu dipersiapkan untuk pelaksanaan kegiatan pelatihan tersebut.
c. Melakukan instalasi sistem.
d. Melakukan Demo Program.
e. Proses feedback dari pengguna website.
f. Pelaporan.

\subsection{Peserta Kegiatan}

Pada proses pelatihan ini peserta kegiatannya adalah pengelola website LPJK.

\subsection{Jadwal Kegiatan}

Jadwal kegiatan pengabdian masyarakat "Sistem Verifikasi Berkas dan Pemberian NRBU" sesuai yang disajikan Tabel 1.

Tabel 1. Jadwal Kegiatan Pengabdian Masyarakat

\begin{tabular}{|c|c|c|}
\hline No & Tanggal & Kegiatan \\
\hline 1 & $\begin{array}{c}18 \text { januari } \\
2020\end{array}$ & $\begin{array}{c}\text { Tatap muka dengan ketua LPJK NTB } \\
\text { Memberi solusi untuk pembuatan website LPJK NTB }\end{array}$ \\
\hline 2 & $\begin{array}{c}30 \text { juni } \\
2020\end{array}$ & Pemaparan contoh Aplikasi sebelum diunggah \\
\hline 3 & 4 juli 2020 & Pelatihan operator pengelola website \\
\hline 4 & 5 juli 2020 & Pengisian kuesioner pengguna website \\
\hline
\end{tabular}

\section{Hasil dan Pembahasan}

\subsection{Implementasi Sistem}

Implementasi sistem ini menggunakan LocalHost/XAMPP. Berikut adalah tampilan dari setiap halaman yang ada di website ini :

\subsubsection{Halaman masuk}

Pada halaman utama website Sistem verifikasi berkas dan pemberian NRBU terdapat formulir pengisian username dan password yang digunakan untuk login ke dalam sistem. Tampilan halaman utama dapat dilihat pada Gambar 1 . 


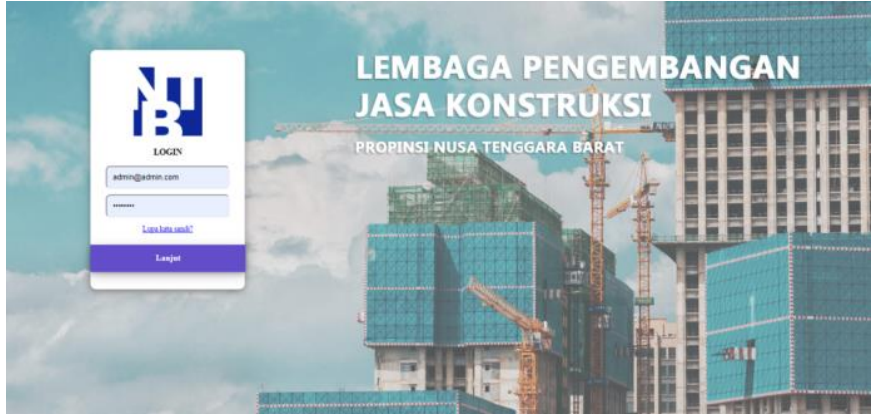

Gambar 1 Halaman Masuk

\subsubsection{Halaman verifikasi berkas}

Pada sistem ini, merupakan proses untuk menaikkan status. User dapat mengelola data sesuai pada Gambar 2. Proses pertama adalah sistem akan menampilkan halaman kelola data pada sisi user, kemudian user dapat menaikkan status mulai dari status 3 , status 4 , status 5 , status 6 .

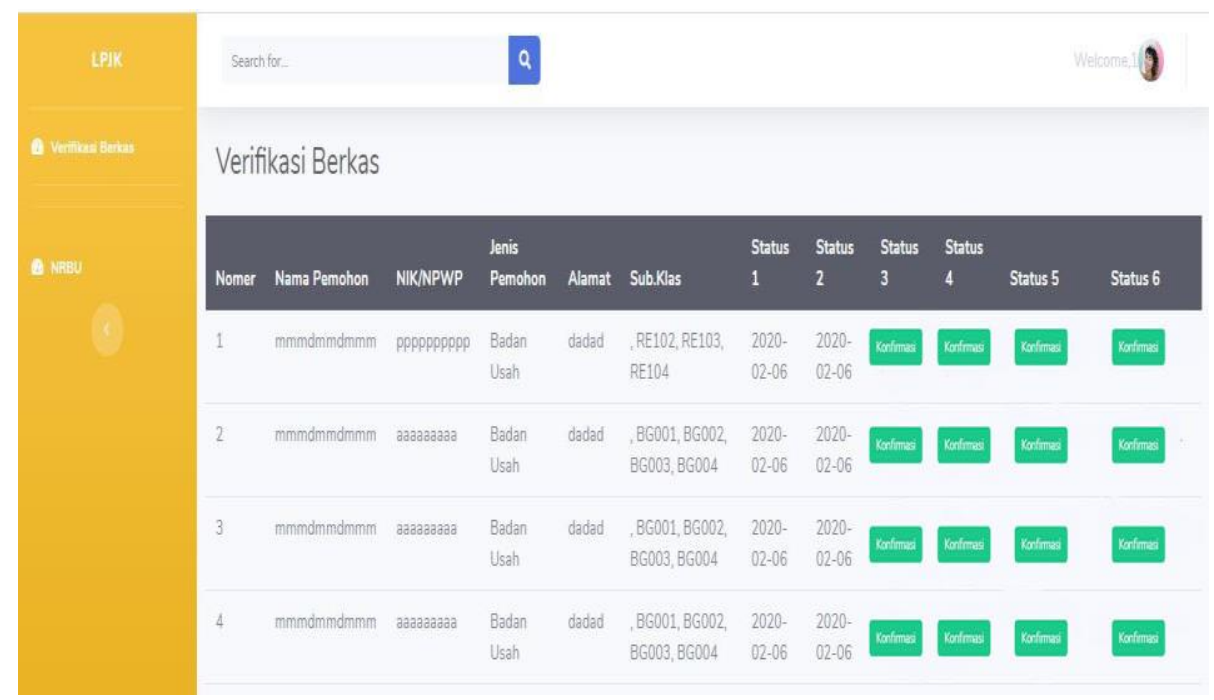

Gambar 2 Halaman Verifikasi Berkas

\subsubsection{Halaman penomoran NRBU}

Pada sistem ini, merupakan proses lanjutan dari menaikkan status berkas. User dapat mengisi NRBU sesuai pada Gambar 3. Proses pertama adalah user harus sudah menaikkan status berkasi sampai status 6 terlebih dahulu selanjutnya user bisa mengisi NRBU.

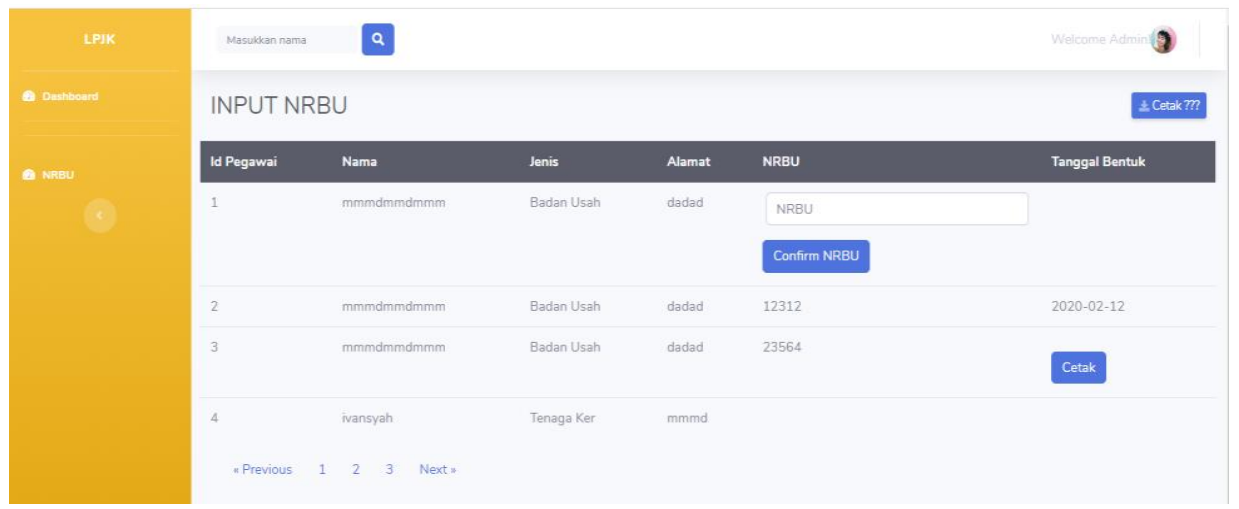

Gambar 3 Halaman Penomoran NRBU

Perancangan aplikasi tentunya bukan solusi yang terbaik jika tidak dilengkapi dengan pembekalan materi yang cukup kepada pegawai LPJK yang akan mengoperasikan aplikasi yang dimaksud. sehingga pada akhir kegiatan pengabdian masyarakat ini diselenggarakan pelatihan dan pembinaan terhadap penggunaan aplikasi pada Juli 2020 (Gambar 4 dan 5). 


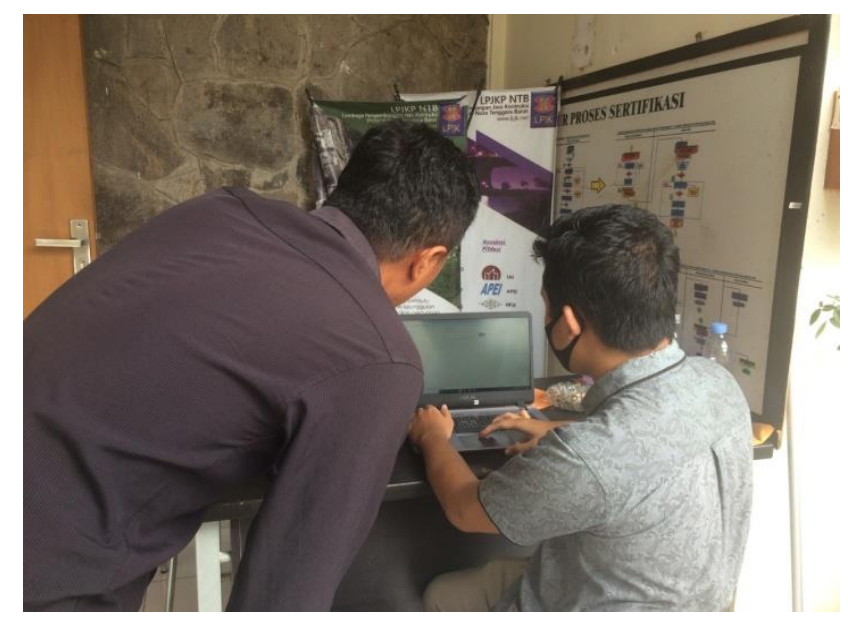

Gambar 4. Pelatihan Kepada Pegawai LPJK

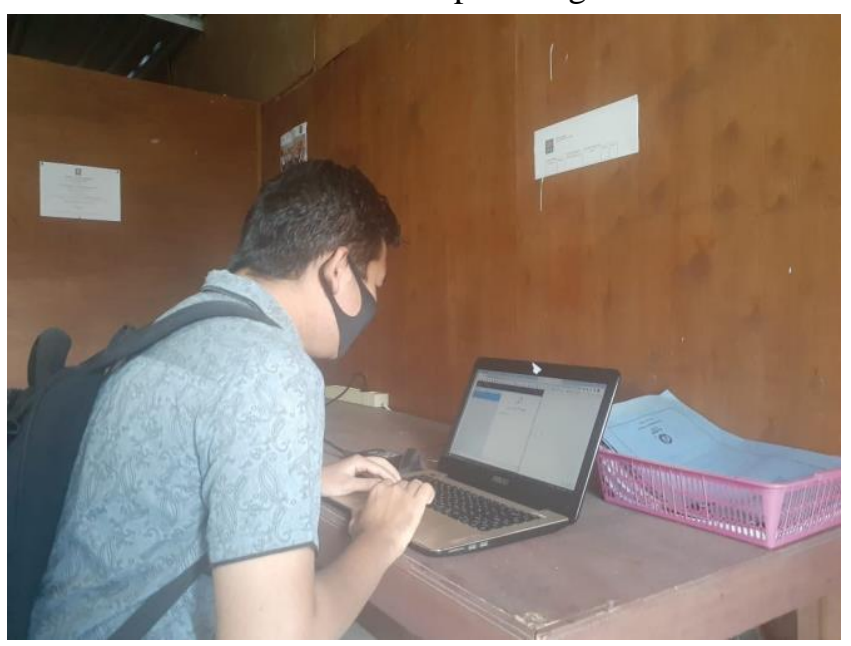

Gambar 5. Sinkronisasi data uji coba pada sistem

\subsection{Hasil Kuisioner}

Uji lab dilakukan oleh beberapa responden atau pengguna yang akan menggunakan sistem. Uji lab dilakukan dengan tujuan agar mengetahui kualitas sistem dari sisi pengguna. Pengujian ini menggunakan kuesioner yang memiliki beberapa pertanyaan yang akan dijawab oleh responden. Tujuan dari pengujian ini adalah untuk mengetahui kualitas sistem[10].

Pengujian ini dilakukan dengan cara mencari responden yang merupakan pegawai LPJK provinsi Nusa Tenggara Barat bagian Badan pelaksana untuk melakukan uji coba sistem dan menjawab pernyataan pada kuesioner yang diberikan. Parameter pengujian yang digunakan pada metode ini adalah :

a. Tampilan sistem sudah sangat baik dan mudah dipahami.

b. Sistem mempermudah pekerjaan pegawai.

c. Sistem sangat menunjang kinerja instansi.

d. Sistem sudah memenuhi syarat sesuai dengan kinerja instansi.

Responden akan diberikan pilihan jawaban dari pertanyaan-pertanyaan di atas, yaitu :

a. SS = Sangat Setuju

b. $\mathrm{S}=$ Setuju

c. $\mathrm{C}=$ Cukup

d. $\mathrm{TS}=$ Tidak Setuju

e. STS $=$ Sangat Tidak Setuju 
Hasil rekapitulasi jawaban responden dihitung dari jawaban berdasarkan pengisian kuesioner dari masing-masing pernyataan. Berikut pada Gambar 6 merupakan grafik persentase jawaban rata-rata hasil pengujian dari 2 responden :

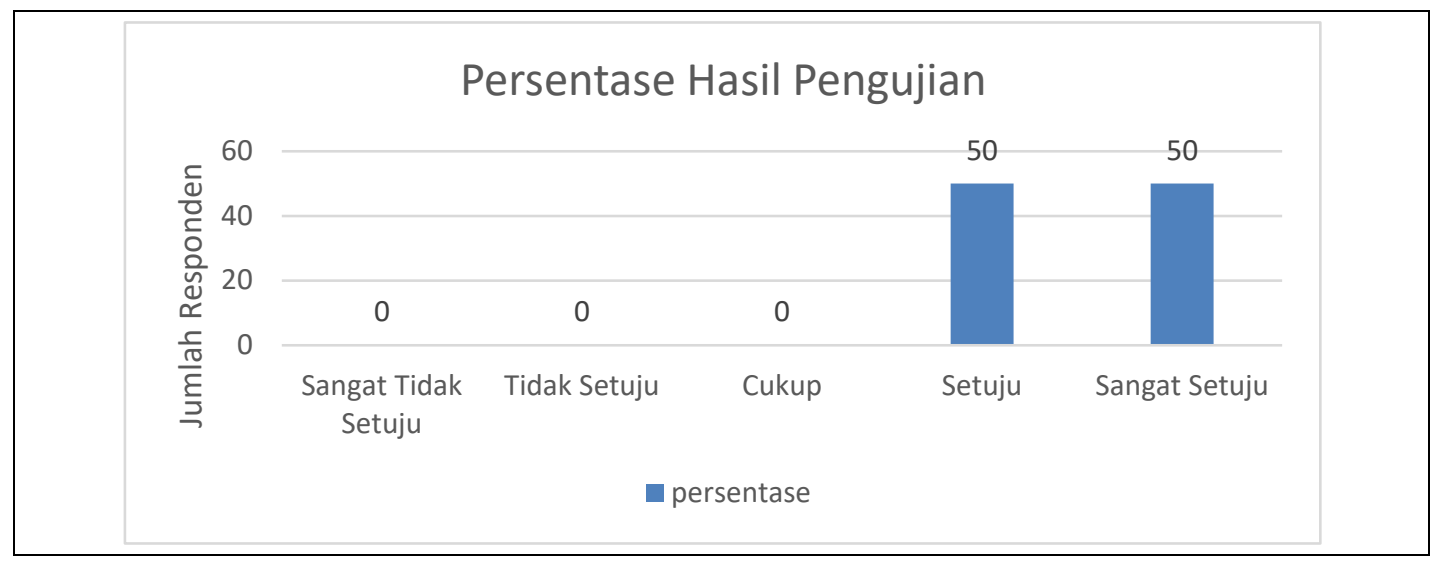

Gambar 6 Persentase hasil pengujian

Pada Gambar 6 menunjukkan bahwa persentase jawaban rata-rata responden didapatkan nilai 0\% untuk jawaban sangat tidak setuju,tidak setuju dan cukup, sedangkan nilai untuk setuju dan sangat setuju masing-masing bernilai 50\% dan 50\%. Sehingga dapat disimpulkan bahwa dari responden setuju kalau sistem ini bermanfaat dan dapat digunakan.

\subsection{Kesimpulan}

\section{KESIMPUlan DAN SARAN}

Berdasarkan pengabdian masyarakat dan pembuatan sistem yang telah dilakukan, sistem verifikasi berkas dan pemberian nomor NRBU berbasis web yang dibangun menyediakan menu untuk melakukan penaikan status berkas mulai dari status 3 sampai status 6 dan memberikan nomor NRBU.

Hasil persentase pengujian dengan metode kuesioner yang diberikan, persentase jawaban rata-rata responden didapatkan nilai $0 \%$ untuk jawaban sangat tidak setuju,tidak setuju dan cukup, sedangkan nilai untuk setuju dan sangat setuju masing-masing bernilai 50\% dan 50\%. Sehingga dapat disimpulkan bahwa dari responden setuju kalau sistem ini bermanfaat dan dapat digunakan.

\subsection{Saran}

Karena masih banyaknya kekurangan dari penulis dalam mengembangkan sistem ini, terdapat beberapa saran untuk dapat membuat sistem ini menjadi lebih baik pada waktu yang akan datang, yaitu perlu adanya notifikasi sertifikat mana saja yang sudah di cetak dan yang belum dicetak. Dalam pengembangan selanjutnya, diharapkan Sistem verifikasi berkas dan pemberian NRBU dapat menjadi lebih kompleks dalam menu maupun fungsinya agar dapat dimanfaatkan lebih maksimal.

\section{DAFTAR PUSTAKa}

[1] M. Ikhsan, N. Adhiatma, and F. Purnama, "Pembuatan Data Base dan Profil Jasa Konstruksi Provinsi Jambi," Knsi 2018, pp. 758-763, 2018.

[2] Jogiyanto, "Konsep Dasar Sistem Informasi," Konsep Dasar Sist. Inf., pp. 1-36, 2017.

[3] J. Jtik and J. Teknologi, "Sistem Informasi Database Sertifikat Keterampilan Kerja ( SKTK ) pada LPJKD Aceh berbasis Web," vol. 4, no. 2, 2020.

[4] A. H. Kridalaksana and A. R. Hakim, "Sistem Pendukung Keputusan Sertifikasi Badan Usaha Pelaksana Jasa Konstruksi Pada BPD GAPENSI Kaltim,” J. Inform. Mulawarman, vol. 5, no. 1, pp. 1-9, 2010.

[5] T. H. Ningrum, M. K. G. Umar, and Subhan, "Sistem Informasi Penerimaan Berkas Badan Usaha Jasa Konstruksi pada Lembaga Pengembangan Jasa Konstruksi (LPJK) Provinsi Maluku Utara,” vol. 3, no. 1, pp. 43-51, 2020.

[6] D. Rosadi and I. Kurniasih, "Sistem Pemberkasan Sertifikasi Guru Berbasis Web," J. Comput. Bisnis, vol. 5, no. 2, pp. 58-65, 2011, [Online]. Available: http://jurnal.stmik-mi.ac.id/index.php/jcb/article/view/67.

[7] L. Utami, "Perancangan Sistem Informasi Verifikasi Berkas Digital Pensiun Pada Kantor Regional Iv Badan Kepegawaian," pp. 6-7, 2016. 
[8] I. Widiasanti, “KAJIAN EFEKTIVITAS MEKANISME SERTIFIKASI TENAGA AHLI MELALUI UNIT SERTIFIKASI TENAGA KERJA LEMBAGA PENGEMBANGAN JASA KONSTRUKSI,” no. 4, p. 2013, 2013.

[9] B. Modul et al., "Raharjo, Budi. 2010. Modul Pemrograman WEB (HTML, PHP, \& MYSQL). Modula .Bandung. Jogiyanto, HM. 2005. Sistem Teknologi Informasi . Andi. Yogyakarta. Jogiyanto, HM. 2005. Analisis dan Desain Sistem Informasi . Andi. Yogyakarta.," no. April, 2012.

[10] S. Syaifullah, I. G. P. S. Wijaya, and A. Y. Husodo, "Satisfaction Information System of Academic Administration Services Based on IPA (Importance Performance Analysis) Study Case in Faculty of Engineering, Mataram University," J. Comput. Sci. Informatics Eng., vol. 2, no. 1, pp. 37-43, 2018, doi: 10.29303/jcosine.v2i1.50. 